\title{
Anatomía e histoquímica de los órganos subterráneos de plantas trepadoras medicinales rioplatenses (Argentina)
}

\author{
Anatomy and Histochemistry of the Underground Organs of \\ Climbing Medicinal Plants from the Shore of Rio de la Plata \\ (Argentina)
}

\author{
Colares Marta N.1,2; Santiago M. Martínez Alonsoํㅜㄹ Etile Spegazzini2 \\ Marcelo P. Hernández ${ }^{1}$; Vanesa G. Perrotta ${ }^{1}$; María C. Novoa ${ }^{1}$; \\ Ana M. Arambarri ${ }^{1 *}$
1 Laboratorio de Morfología Comparada de Espermatófitas (LAMCE), Facultad de Ciencias Agrarias y Forestales, Universidad Nacional de La Plata, 60 y 119, CC31, (1900) La Plata, Buenos Aires, Ar- gentina.
2 Facultad de Ciencias Exactas y Naturales, Universidad de Belgrano.
* Autor corresponsal: anaramba@yahoo.com.ar; botgral@agro.unlp.edu.ar

\begin{abstract}
> Resumen - Colares Marta N.; Santiago M. Martínez Alonso; Etile Spegazzini; Marcelo P. Hernández; Vanesa G. Perrotta; María C. Novoa; Ana M. Arambarri. 2017. "Anatomía e histoquímica de los órganos subterráneos de plantas trepadoras medicinales rioplatenses (Argentina)". Lilloa 54 (2). El objetivo de este estudio fue caracterizar los rizomas y raíces por sus atributos histológico-estructurales y determinar la presencia de compuestos químicos que faciliten la identificación de los taxones de muestras enteras o fragmentadas de los mismos. Se analizó material fresco recolectado en el área de estudio y ejemplares de herbario (LPAG). Para las preparaciones anatómicas se procedió con técnicas usuales para microscopía óptica. Se realizaron reacciones histoquímicas para identificar almidón, mucílagos, lípidos y taninos. Los principales rasgos micrográficos resultaron: las características de las células y número de estratos celulares de la rizodermis y exodermis; el desarrollo de la peridermis; las peculiaridades del parénquima cortical y de la estela; el engrosamiento de las paredes celulares de las células corticales adyacentes a la endodermis y de la endodermis; la presencia de reservorios secretores y tipos de cristales. Sobre la base de los datos obtenidos se generaron tablas comparativas con los grupos químicos identificados y construyeron claves dicotómicas de las especies que constituyen una herramienta de valor en el control de calidad botánica.

Palabras clave: Enredaderas, estructura de los tejidos, química, lianas, raíces, rizomas.
\end{abstract}

- Abstract - Colares Marta N.; Santiago M. Martínez Alonso; Etile Spegazzini; Marcelo P. Hernández; Vanesa G. Perrotta; María C. Novoa; Ana M. Arambarri. 2017. "Anatomy and Histochemistry of the Underground Organs of Climbing Medicinal Plants from the Shore of Rio de la Plata (Argentina)". Lilloa 54 (2). The aim of this paper was to characterize the histological, structural and histochemical attributes of rhizomes and roots in order to facilitate the identification of species from whole or fragmented material. Fresh material, collected in the area of study, and herbarium specimens (LPAG) were analyzed. For the anatomical preparations we proceeded with usual techniques for optical microscopy. Histochemical tests to recognize starch, mucilage, lipophilic substances, and tannins were performed. The main micrographic features were: cell shapes and cell wall thickenings of the rhizodermis and exodermis; the development of the peridermis; peculiarities of the cortical parenchyma and the stele; the thickening degree of the cell walls of cortical cells adjacent to the endodermis and the endodermis; the presence of secretory reservoirs and crystal types. Comparative tables with histochemical results and diacritic keys using micrographic characters from rhizome and roots were generated as a tool for quality control.

Keywords: Tissue structure, chemistry, climbing plants, rhizomes, roots, scandent plants.

Recibido: 22/08/17 - Aceptado: 06/11/17 


\section{INTRODUCCIÓN}

Este trabajo es una nueva contribución al estudio de la anatomía comparada de los órganos vegetativos de especies rioplatenses utilizados en la medicina popular. La región rioplatense se extiende desde Diamante en la provincia de Entre Ríos (32 ${ }^{\circ} 4^{\prime} 0^{\prime \prime} \mathrm{S} 60^{\circ}$ $39^{\prime} 0^{\prime \prime} O$ ) hasta Punta Lara en la provincia de Buenos Aires (3447'28"S 57059'49”O). Dentro de esta región, el estudio se centra en las especies medicinales que habitan la parte inferior del Delta del Paraná, isla Martín García y ribera del Río de la Plata, para ello se han tomado como base los trabajos de Pochettino et al. (1997); Lahitte y Hurrell (1996; 2000); Lahitte et al. (2004); Hurrell (2009); Hernández et al. (2009, 2010, 2013, 2015a). Los resultados de las investigaciones previas quedaron plasmados en las publicaciones de los tallos aéreos y subterráneos de siete especies herbáceas de Monocotiledóneas (Novoa et al., 2012), la anatomía de los tallos aéreos de 37 especies de Dicotiledóneas (Arambarri et al., 2013), las raíces de 22 especies (Colares et al., 2014), las hojas de 62 especies (Hernández et al., 2015b), la anatomía foliar de Commelinaceae (Novoa y Arambarri, 2016) y la anatomía de órganos subterráneos de Monocotiledóneas medicinales, parte I (acuáticas y palustres) (Arambarri et al., 2016), estando actualmente aceptada para su publicación, la parte II sobre órganos subterráneos de Dicotiledóneas medicinales palustres (Perrotta et al., 2017). Las propiedades medicinales de las plantas que crecen en la región fueron estudiadas (Hieronymus, 1882; Domínguez, 1928; Toursarkissian, 1980; Lahitte y Hurrell, 1996; Lahitte et al., 2004; Alonso y Desmarchelier, 2005; Rondina et al., 2008, 2010; Barboza et al., 2006, 2009). Algunas de los usos más frecuentes de los órganos subterráneos son: Araujia sericifera como galactógeno (Barboza et al., 2006; Bucciarelli et al., 2008); la raíz de Dolichandra unguis-cati como astringente y antidisentérico (Lahitte et al., 2004). Las raíces de Ipomoea cairica e $I$. indica como purgante y febrífugo (Lahitte y Hurrell, 2000). Las zarzaparrillas
(Herreria montevidensis, Muehlenbeckia sagittifolia y Smilax campestris) tienen en sus órganos subterráneos propiedades como antiácido, diurético, antinefrítico, antirreumático, se venden en herboristerías y durante mucho tiempo Muehlenbeckia fue adulterante de Smilax (Lahitte y Hurrell, 2000; Lahitte et al., 2004; Hurrell, 2009; Hurrell et al., 2011). Passiflora caerulea es conocida por la venta en herboristerías de las partes aéreas para uso como sedante; para las raíces se citan sus propiedades como vermífugo y desinflamante, sin embargo, el exceso de la misma puede resultar tóxica (Alonso y Desmarchelier, 2005; Barboza et al., 2009). Gattuso (1995); Bucciarelli et al. (2008) y Sella et al. (2013) entre otros, han analizado la anatomía de los órganos de plantas trepadoras. Estas y otras obras citadas en la discusión, han servido como base para nuestro estudio, desarrollado con la convicción de que la profundización del conocimiento de anatomía comparada de los órganos utilizados como drogas medicinales es de gran valor en el proceso de control botánico. En esta entrega, como parte del proyecto de estudio de los órganos usados en la medicina popular de plantas acuáticas, palustres, trepadoras y volubles, analizamos los rizomas de Muehlenbeckia sagittifolia y Smilax campestris y las raíces de las dos especies mencionadas más Araujia sericifera, Dolichandra unguiscati, Herreria montevidensis, Ipomoea cairica, I. indica y Passiflora caerulea, clasificadas como plantas escandentes: lianas (leñosas) y enredaderas (herbáceas) (Ferrucci et al., 1999; Cabanillas y Hurrell, 2012). Los resultados son presentados en tablas comparativas y claves dicotómicas con caracteres que permitirían la identificación de las especies a partir de muestras fragmentadas con fines de control de calidad botánica.

\section{MATERIALES Y MÉTODOS}

\section{MATERIAL ESTUDIADO}

Se recolectaron plantas en la ribera del Río de la Plata y localidades próximas, algunas muestras fueron tomadas de plantas cultivadas en el Jardín Botánico y Arboretum 
«C. Spegazzini» de la Facultad de Ciencias Agrarias y Forestales (JByA, FCAyF), Universidad Nacional de La Plata. También se estudiaron ejemplares de herbario (LPAG) de la misma Institución.

Material estudiado: ARGENTINA, provincia de Buenos Aires.

Araujia sericifera Brot. (Apocynaceae): Pdo. La Plata, La Plata, 18-III-1995, Bayón 192 (LPAG); Pdo. Berisso, camino a La Balandra, 4-II-2017, M.P. Hernández 230 y 231 (LPAG).

Dolichandra unguis-cati (L.) L.G. Lohmann (Bignoniaceae): Pdo. La Plata, La Plata, Jardín Botánico y Arboretum «C. Spegazzini», Facultad de Ciencias Agrarias y Forestales (FCAyF), UNLP, XI-2016, 30-VI2017, Montes de Oca y Arambarri 516, 521 (LPAG).

Herreria montevidensis Klotzsch ex Griseb. (Herreriaceae): Pdo. La Plata, La Plata, Jardín Botánico y Arboretum «C. Spegazzini» (FCAyF), UNLP, VI-2015, XI-2016, Montes de Oca y Arambarri 514, 522 (LPAG).

Ipomoea cairica (L.) Sweet (Convolvulaceae): Pdo. Magdalena, Reserva natural «El Destino» Fundación Elsa Shaw de Pearson, V-2016, Martínez Alonso 115 (LPAG); Pdo. La Plata, La Plata, Jardín Botánico y Arboretum «C. Spegazzini» (FCAyF), UNLP, V-2016, Arambarri 517 (LPAG).

Ipomoea indica (Burm. f.) Merr. (Convolvulaceae): Pdo. La Plata, La Plata, Facultad de Ciencias Naturales y Museo, V-2016, Arambarri 512; 20-IV-2017, Montes de Oca y Arambarri 518 (LPAG); Loc. Manuel B. Gonnet, 27-IV-2017, Hernández 232, 233 (LPAG).

Muehlenbeckia sagittifolia (Ortega) Meisn. (Polygonaceae): Pdo. La Plata, La Plata, Jardín Botánico y Arboretum «C. Spegazzini», (FCAyF), UNLP, V-2016, Arambarri 515 (LPAG); 15-XI-2016, Arambarri 520 (LPAG).

Passiflora caerulea L. (Passifloraceae): Pdo. La Plata, La Plata, Jardín Botánico y Arboretum «C. Spegazzini» (FCAyF), UNLP, III-2015, M.C. Novoa s. n.; 11-IV-2016, Montes de Oca \& Arambarri 519 (LPAG).

Smilax campestris Griseb. (Smilacaceae):
Pdo. La Plata, La Plata, Jardín Botánico y Arboretum «C. Spegazzini» (FCAyF), UNLP, VI-2016, Colares \& Arambarri 513 (LPAG).

\section{MÉTODOS}

Se analizaron, según su uso medicinal, raíces, rizomas o ambos de uno a cuatro ejemplares por especie. Para facilitar la comprensión en el texto y tablas, estos órganos se tratan por separado. Dada las peculiaridades de los sistemas subterráneos de algunas especies tratadas, se ha incluido una breve descripción e ilustración morfológica de las raíces de Herreria montevidensis y Dolichandra unguis-cati. En las Tablas 1 y 2 se muestran los resultados de las reacciones histoquímicas y los tipos de cristales existentes en cada órgano y especie. Los caracteres anatómicos permitieron generar dos claves dicotómicas, una para rizomas y otra para raíces que incluye las ocho especies estudiadas. En el Apéndice 1, se presentan las especies -por orden alfabético del género- con su familia, nombres vernáculos (de la Peña y Pensiero, 2004) y usos medicinales.

\section{MicROSCOPÍA ÓPTICA}

Para el estudio de la anatomía, el material fresco se lavó y conservó en una solución de formaldehido, ácido acético, alcohol etílico 70\% (FAA 70) (Johansen, 1940). Posteriormente se realizaron cortes transversales a mano alzada, los que fueron seleccionados, decolorados y lavados con agua destilada tres veces. Se practicaron tinciones con safranina alcohólica 80\%, doble coloración con azul de Alcian y safranina (Luque et al., 1996). En todos los casos se montaron en gelatina-glicerina y sellaron con esmalte de uñas. El diámetro de los órganos estudiados e ilustrados se expresó en (mm). El arreglo de los tejidos formando las estructuras se examinaron haciendo uso de un microscopio óptico (MO) Leitz SM Lux. Las microfotografías fueron tomadas con MO Gemalux equipado con cámara Motic 1000 y software Motic Image Plus 2.0; mientras que las imagenes macroscópicas de raíces se tomaron con una cámara Sony Zeiss DSC-W30. La no- 
Tabla 1. Resultados de las pruebas histoquímicas realizadas en los rizomas de las especies estudiadas. Ref.: (+) presencia; [-] ausencia.

\begin{tabular}{lccccc}
\hline Especie & Almidón & Lípidos & Mucílagos & Taninos & Cristales \\
\hline Muehlenbeckia sagittifolia & + & + & - & + & drusas \\
\hline Smilax campestris & + & + & - & - & rafidios \\
\hline
\end{tabular}

Tabla 2. Resultados de las pruebas histoquímicas realizadas en las raíces de las especies estudiadas. Ref.: [+] presencia; [-] ausencia.

\begin{tabular}{lccccc}
\hline Especie & Almidón & Lípidos & Mucílagos & Taninos & Cristales \\
\hline Araujia sericifera & + & + & - & - & drusas \\
\hline Dolichandra unguis-cati & & & & rafidios \\
(parte engrosada) & + & + & - & - & - \\
(raíz) & - & + & - & - & rafidios \\
\hline Herreria montevidensis & - & + & - & - & drusas \\
\hline Ipomoea cairica & + & + & - & - & estiloides \\
\hline Ipomoea indica & + & + & - & drusas \\
\hline Muehlenbeckia sagittifolia & - & + & - & - & - \\
\hline Passiflora caerulea & + & + & - & - & - \\
\hline Smilax campestris & + & & & - & - \\
\hline
\end{tabular}

menclatura botánica se actualizó haciendo uso de los sitios www.darwin.edu.ar y trópicos.org (consultados: junio 2017).

\section{TÉCNICAS HISTOQUÍMICAS}

Sobre cortes del material fresco se practicaron las técnicas de identificación de almidón con Lugol (iodo y ioduro de potasio, IKI) (Ruzin, 1999); para sustancias lipofílicas se empleó una solución alcohólica saturada de Sudan IV (Zarlavsky, 2014); para los mucílagos se utilizó azul brillante de cresilo 1\% (Cosa et al., 2014) y los taninos se identificaron mediante el reactivo cloruro férrico al $10 \%$ y carbonato de sodio al $2 \%$ (Zarlavsky, 2014).

\section{RESULTADOS}

\section{RIZOMAS \\ Muehlenbeckia sagittifolia}

(Fig. 1A-C)

El corte transversal de un rizoma de 5 $\mathrm{mm}$ de diámetro presenta peridermis donde se visualizan claramente los estratos de súber. En la corteza se distribuyen drusas, esclereidas y fibras que rodean al anillo de floema secundario, además tanto en la cor- teza como en el floema hay idioblastos con taninos (Fig. 1A, B). El xilema secundario rodea la amplia médula en cuyo parénquima abunda el almidón de granos simples esferoidales (Fig. 1C).

\section{Smilax campestris \\ (Fig. 1D, E)}

El corte transversal de un rizoma de 9 $\mathrm{mm}$ de diámetro, presenta epidermis unistrata con pared periclinal externa lipídica. El parénquima cortical está separado del parénquima medular por un anillo de esclerénquima de 6-8 capas celulares, de espesor. En la parte interna, se observa la atactostela con haces colaterales cerrados ubicados en el anillo de fibras y dispersos en el parénquima medular (Fig. 1D). En el parénquima cortical se hallaron rafidios (Fig. 1E) y en el parénquima medular se identificó almidón.

CLAVE PARA LA DETERMINACIÓN DE LAS ESPECIES BASADA EN LOS CARACTERES DE LA ANATOMÍA DEL RIZOMA

1 Rizoma con estructura primaria y luego secundaria. Presencia de drusas, ausencia de rafidios ..... Muehlenbeckia sagittifolia 


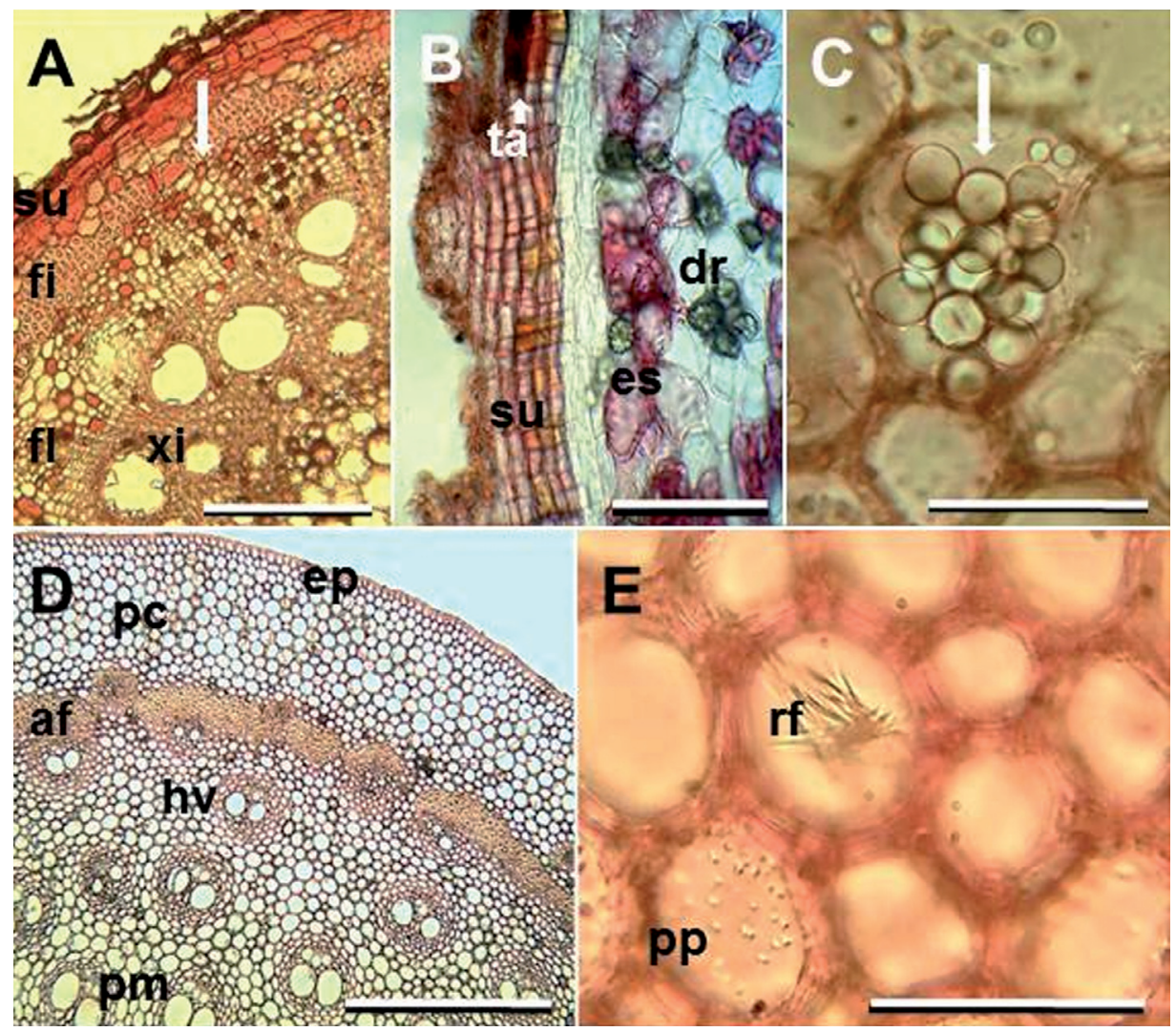

Fig. 1. Rizomas, anatomía e histoquímica. Muehlenbeckia sagittifolia: A] Corte transversal mostrando estratos de súber, casquetes de fibras, el floema y xilema secundario rodeando la médula; se visualizan células taníferas en el floema y corteza (flecha). B) Detalle de la peridermis con taninos en el súber. Drusas y esclereidas en la corteza. C) parénquima medular con granos de almidón simple con hilo central (flecha). Smilax campestris: D) Vista general del rizoma en corte transversal. Epidermis, anillo esclerenquimático separando el parénquima cortical del parénquima medular con haces colaterales cerrados, en el anillo de fibras y en el parénquima medular. E) Parénquima medular formado por células con paredes engrosadas con puntuaciones, algunas contienen rafidios. Ref.: af, anillo de fibras; dr, drusas; ep, epidermis; es, esclereidas; fi, fibras; fl, floema; hv, haz vascular; pc, parénquima cortical; pm, parénquima medular; pp, pared punteada del parénquima medular; rf, rafidios; su, súber; ta, taninos; xi, xilema. Escalas: A: $200 \mu \mathrm{m}$; B: $100 \mu \mathrm{m}$; $, \mathrm{E}: 50 \mu \mathrm{m} ; \mathrm{D}: 500 \mu \mathrm{m}$.

1' Rizoma solo con estructura primaria. Ausencia de drusas, presencia de rafidios ................. Smilax campestris

\section{RAÍCES}

\section{Araujia sericifera}

(Fig. 2)

El corte transversal de una raíz de 1,0 mm de diámetro, mostró estructura secundaria con peridermis donde se destacan 6-10 estratos de súber formado por células rectangulares con paredes delgadas, suberificadas
(Fig. 2 A). La corteza está formada por 5-6 capas de parénquima con drusas y grupos de esclereidas dispuestas formando un anillo discontinuo alrededor del cilindro central (Fig. 2A). El floema secundario forma un anillo estrecho (Fig. 2A, B), con numerosos tubos laticíferos, almidón y drusas (Fig. 2B), rodea la masa de xilema secundario que ocupa el centro de la raíz. 

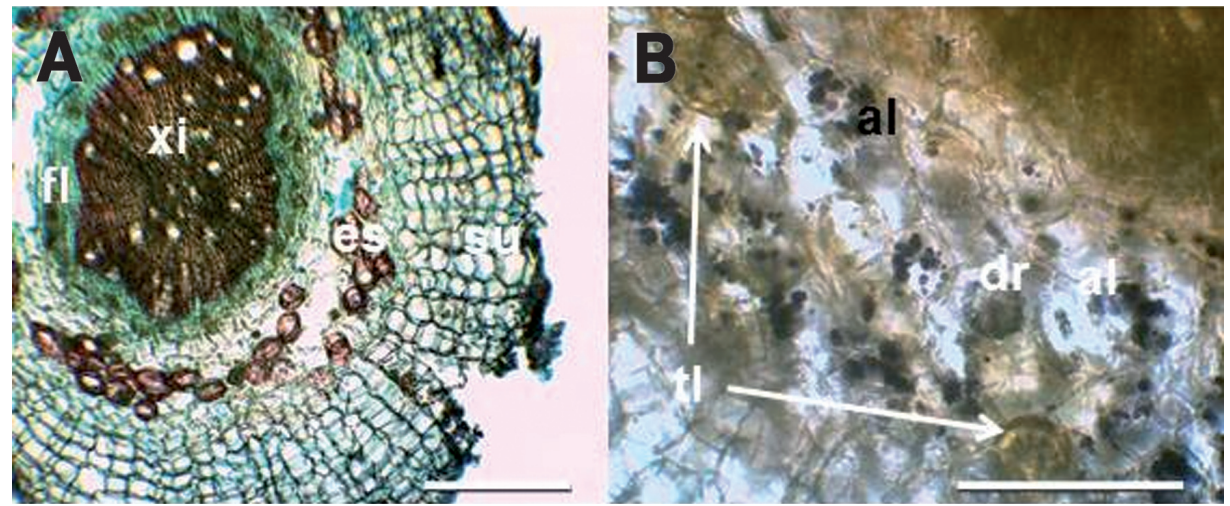

Fig. 2. Raíz de Araujia sericifera: A] Vista general en corte transversal mostrando el súber pluristrato, parénquima con esclereidas y estrecho anillo de floema secundario con tubos laticíferos que rodea al xilema secundario que ocupa el centro de la raíz. B) Detalle del floema mostrando drusas, almidón y tubos laticíferos. Ref.: al, almidón; dr, drusas; es, esclereidas; fl, floema; su, súber; tl, tubos laticíferos; xi, xilema. Escalas: A: $200 \mu \mathrm{m}$; B: 100 m.

\section{Dolichandra unguis-cati}

(Fig. 3 y Fig. 4)

Una raíz con diámetro aproximado de 0,2-0,4 mm ya tiene estructura secundaria (Fig. 3 A, B). Se observan varios estratos de súber y en el parénquima cortical la endodermis con banda de Caspary visualizada como puntos de Caspary; el periciclo está formado por células elípticas proporcionalmente grandes; en el floema comienzan a diferenciarse grupos de fibras y el conjunto rodea al xilema secundario (Fig. 3B).

En un estado de crecimiento más avanzado el sistema subterráneo completo, está formado por tres partes (Fig. 3C1-3), la primera parte indicada en la Fig. $3 \mathrm{C}$ con el número 1 , la segunda parte indicada con el número 2 , engrosada de manera tuberosa y la tercera parte indicada con el número 3 . La primera y segunda parte presentan una estructura propia, por lo que se especula se trataría del hipocótilo, sector de estructura intermedia entre la raíz y el tallo (Fig. 3C12). La tercera parte es la raíz propiamente dicha (Fig. 3C3).

La primera parte estrecha (Fig. 3C1) con un diámetro de 3,0-3,5 mm, presenta en el corte transversal (Fig. 3D), peridermis donde se destacan 5-7 estratos de súber. En la parte más interna de la corteza parenquimática se observan grupos de fibras dispuestos en dos círculos o anillos concéntricos discon- tinuos, los cuales están separados entre sí y del floema secundario por parénquima; el floema secundario está atravesado en su parte media por un anillo de fibras. El xilema secundario presenta su límite interno pentalobado, limitando la médula formada por parénquima (Fig. 3D). La segunda parte, el sector engrosado (Fig. 3C2), con 7,0-15,0 $\mathrm{mm}$ de diámetro presenta en el corte transversal (Fig. 4A, B), peridermis y un extenso parénquima cortical, en el parénquima cortical externo, abundan fibras solitarias y en pequeños grupos, dispuestos de manera dispersa (Fig. 4A); en el parénquima cortical interno, los grupos de fibras están ordenados en dos o tres círculos o anillos discontinuos (Fig. 4A, B). Estos anillos de fibras adoptan un contorno lobado (Fig. 4B), los anillos de fibras más internos forman parte del floema secundario el cual también tiene contorno lobado y rodea al xilema secundario (Fig. 4A, B). Este último es discontinuo y está formado por cinco grupos mayores ubicados en los lóbulos, luego se forman grupos de xilema secundario, menores, en los sectores interlobulares. El conjunto rodea la amplia médula parenquimática pentalobada (Fig. 4B). En el parénquima cortical también se encontraron grupos de esclereidas (Fig.4 C), rafidios y almidón (Fig. 4D), sustancias lipídicas (Fig. 4E). En el corte transversal de la tercera porción de 3,0-3,5 mm de diámetro 
(Fig. 3C3), hallamos la estructura secundaria de la raíz propiamente dicha, la cual presenta peridermis, destacándose 6-8 estratos de súber, la corteza parenquimática donde aparecen grupos de fibras formando 2-3 círculos discontinuos alrededor del floema secundario. Este en su parte media es atravesado por un círculo continuo de fibras y rodea al xilema secundario. En el centro hay médula formada por parénquima (Fig. 4F). En un estado más avanzado de crecimiento de la raíz, el xilema secundario ocupa todo el centro de la misma.

\section{Herreria montevidensis}

(Fig. 5)

El sistema radical de esta especie es fasciculado, formado por raíces tuberosas

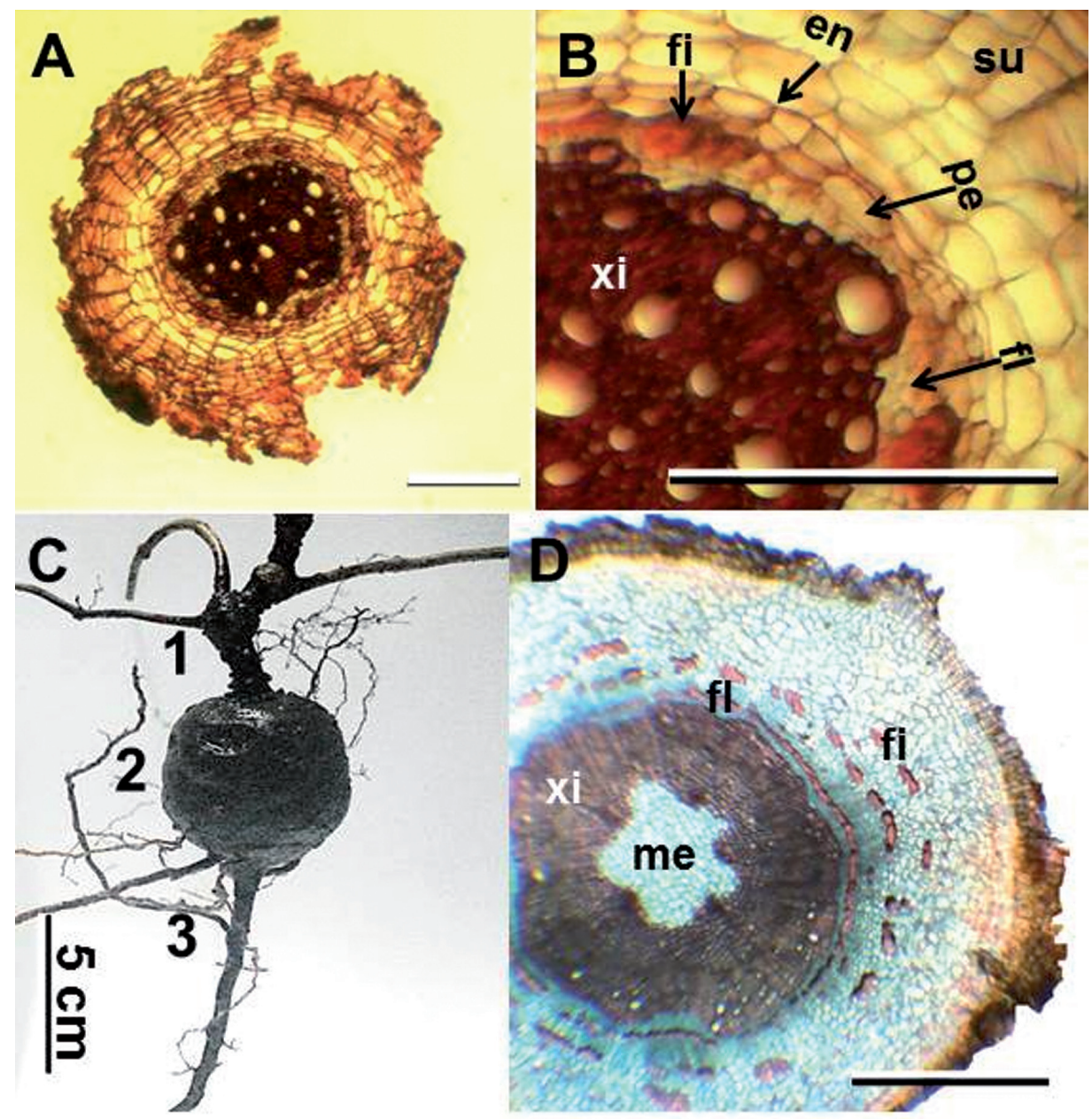

Fig. 3. Sistema subterráneo de Dolichandra unguis-cati. A) Raíz con estructura secundaria inicial. B) Detalle de la raíz mostrando el súber de la peridermis, endodermis con banda de Caspary (se observan los puntos de Caspary, flecha); el periciclo, grupos de fibras, floema secundario y en el centro el xilema secundario. C) Vista macroscópica de las partes del sistema subterráneo de Dolichandra unguis-cati: donde se observan las partes 1-3; 11 y 2 se consideran hipocótilo; 3, raíz propiamente dicha). D) Corte transversal de la parte 1 , donde se destaca la presencia de fibras en la corteza y en el floema; el xilema secundario rodeando la médula parenquimática, ambos en su línea de contacto pentabolados. Ref.: en, endodermis; fi, fibras; fl, floema; me, médula; pe, periciclo; su, súber; xi, xilema. Escalas: A, B: $100 \mu \mathrm{m} ; \mathrm{D}: 500 \mu \mathrm{m}$. 


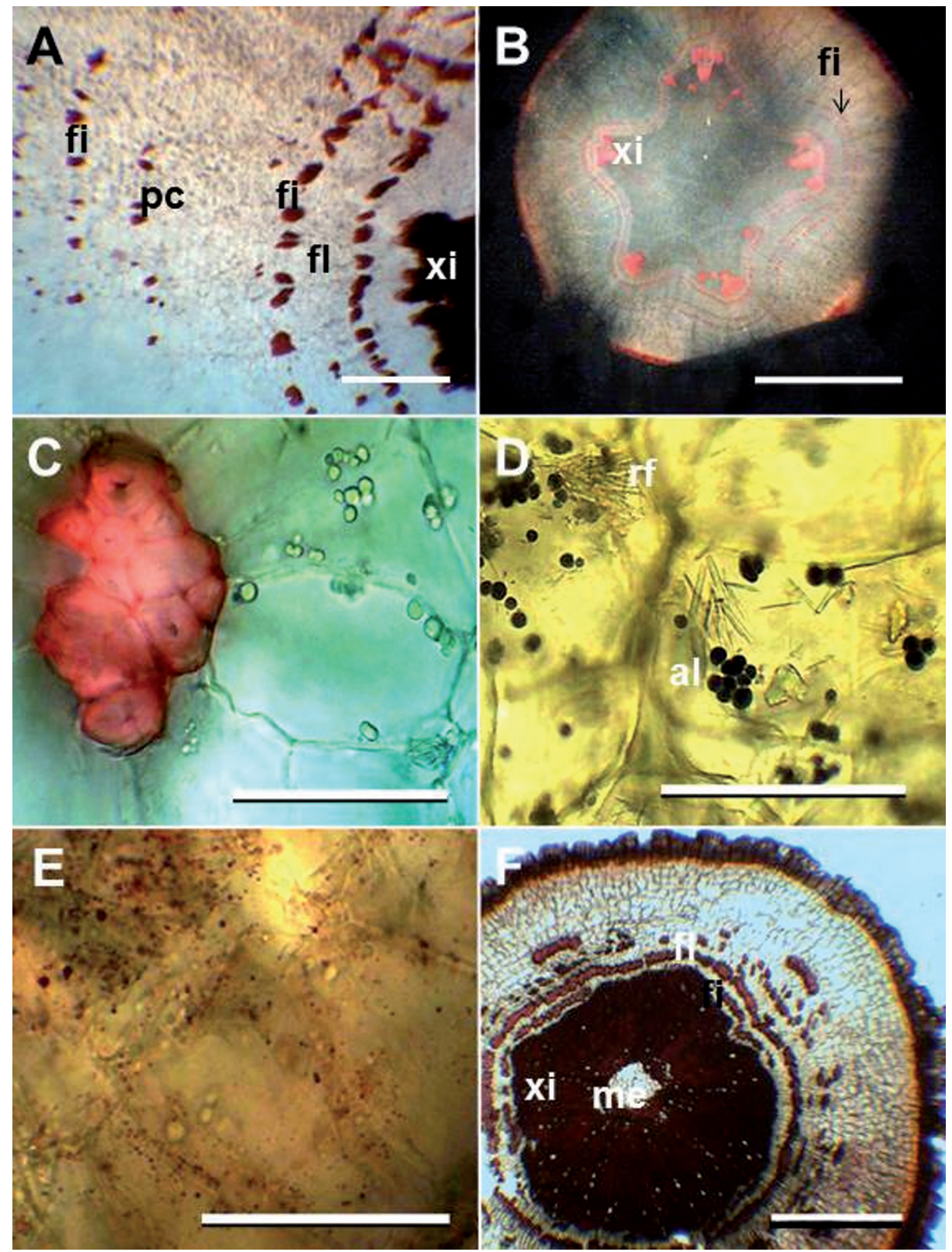

Fig. 4. Sistema subterráneo de Dolichandra unguis-cati (continuación). A) Corte transversal de la parte 2, tuberosa: parénquima cortical donde se observan dispersas, las fibras solitarias o en pequeños grupos y luego formando círculos en la corteza interna y el floema. B] Vista general del corte transversal de la parte tuberosa, mostrando la estructura pentalobada con predominio del tejido parenquimático. Se ven tres círculos de fibras, dos corticales y uno en el floema; el xilema secundario discontinuo, en los lóbulos y grupos menores en los sectores interlobulares. Médula amplia. C) Esclereidas y almidón en el parénquima cortical del sector tuberoso (parte 2). D) Rafidios y almidón en el parénquima del mismo sector. E) Gotitas de sustancias lipídicas en el parénquima cortical del mismo sector. F) Corte transversal de la raíz propiamente dicha (parte 3). Se observa la estructura secundaria caracterizada por la peridermis y tejido vascular secundarios con médula central. Ref.: al, almidón; fi, fibras; fl, floema; me, médula; pc, parénquima cortical; rf, rafidios; xi, xilema. Escalas: A: 1 mm; B: 5 $\mathrm{mm} ; \mathrm{C}, \mathrm{D}, \mathrm{E}: 50 \mu \mathrm{m} ; \mathrm{F}: 500 \mu \mathrm{m}$. 


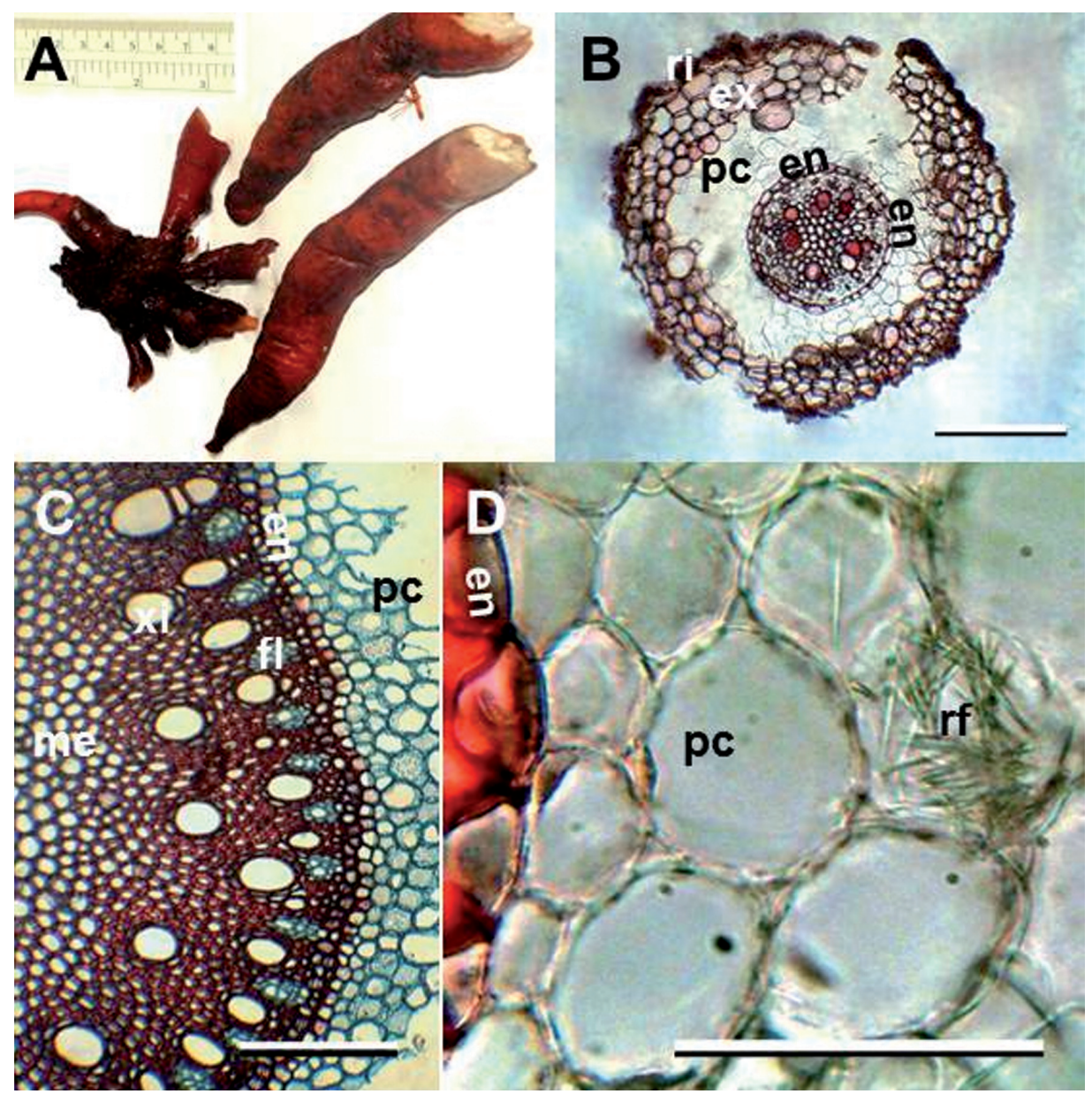

Fig. 5. Raíz de Herreria montevidensis. A] Vista general de las raíces tuberosas. B] Raíz en corte transversal con estructura primaria donde se destaca la amplia exodermis de 8-10 capas con paredes esclerificadas; el parénquima cortical; la endodermis con engrosamiento en $U$ y el cilindro central poliarca. C) Detalle del parénquima cortical de células con paredes delgadas y su capa más interna diferenciada en la endodermis con tercer engrosamiento en U. Los tejidos del cilindro central esclerificados, excepto el floema. D) Detalle del parénquima cortical con rafidios y la endodermis con engrosamiento en U. Ref.: en, endodermis; ex, exodermis; fl, floema; me, médula; pc, parénquima cortical; ri, rizodermis; xi, xilema. Escalas: B: $500 \mu \mathrm{m}$; C: $200 \mu \mathrm{m}$; D: $50 \mu \mathrm{m}$.

de color castaño-rojizo (Fig. 5A). El corte transversal de una raíz de 1,0-1,5 mm de diámetro (Fig. 5B) presenta rizodermis unistrata con paredes delgadas, seguida de una exodermis pluristrata, formada por 4-6 (-8) capas de células hexagonales con paredes ligeramente engrosadas y suberificadas (Fig. 5B), a continuación se ubica el parénquima cortical de células isodiamétricas, con paredes celulósicas delgadas, que dejan pequeños espacios intercelulares, cuya capa más interna, la endodermis, sufre los tres engrosamientos de sus paredes mostrando en la imagen el tercer engrosamiento en U (Fig. 5B, C y D). En el cilindro central hallamos el periciclo y los tejidos vasculares primarios, en disposición alterna y radiada y ubicados en la región periférica de la médula. La médula es amplia. Como pertenece a la clase Monocotiledóneas, la estructura poliarca se mantiene cuando la raíz alcanza mayores diámetros, incrementando su parénquima 
cortical y sufriendo lignificación de todos los tejidos del cilindro central, excepto parte del floema (fig. 5C). En el parénquima cortical hay idioblastos con rafidios (Fig. 5D).
Ipomoea cairica e I. indica

(Fig. 6)

En el corte transversal de una raíz de 0,3-0,6 mm de diámetro, hallamos la es-
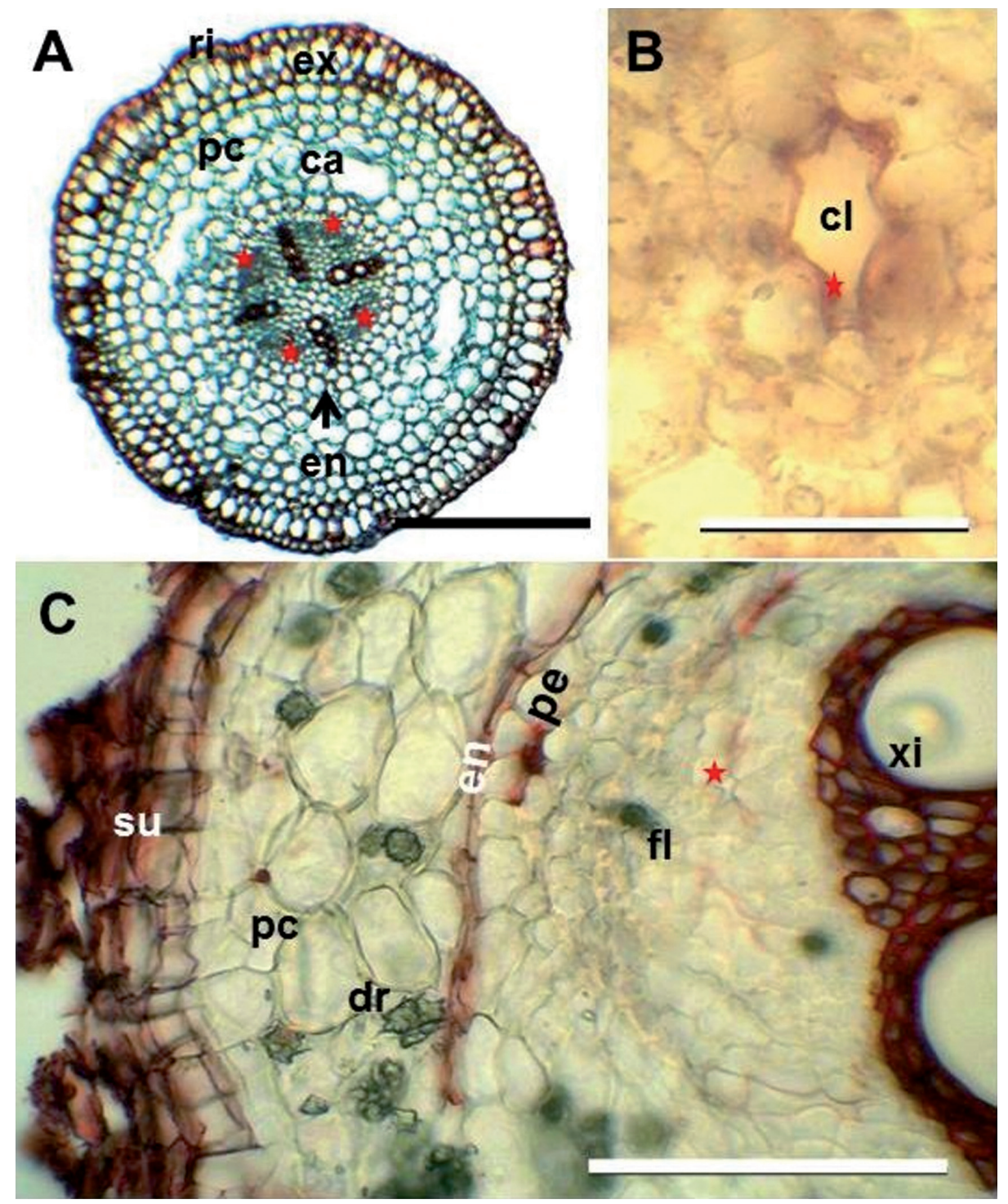

Fig. 6. Raíz de Ipomoea spp. A) Estructura primaria donde se destaca la rizodermis y exodermis, las cámaras aeríferas en el parénquima cortical y la estructura tetrarca (con estrellas se indica la ubicación de las células laticíferas en el floema). B) Detalle de una célula laticífera en el floema, mostrando el contorno poligonal y la pared lipídica (reactivo Sudan IV). C) Detalle de la estructura secundaria en corte transversal, destacando el súber, el parénquima con numerosas drusas (I. indica); la endodermis algo aplastada y discontinua (por la acción del crecimiento secundario); el periciclo y el floema y xilema secundarios. En el floema se señaló una célula laticífera. Ref.: ca, cámara; cl, célula laticífera; dr, drusas; en, endodermis; ex, exodermis; fl, floema secundario; pc, parénquima cortical; pe, periciclo; ri, rizodermis; su, súber; xi, xilema secundario; estrellas señalan ubicación de células laticíferas. Escalas: A: $200 \mu \mathrm{m}$; B: $50 \mu \mathrm{m}$; C: $100 \mu \mathrm{m}$. 
tructura primaria (Fig. 6A). La rizodermis es unistrata, sus células presentan la pared periclinal externa engrosada; la exodermis está formada por dos capas celulares desiguales, la externa con células hexagonales radialmente alargadas y proporcionalmente grandes, mientras la interna está formada por células pequeñas, ambas con paredes engrosadas y suberificadas (Fig. 6A). La corteza parénquimática presenta 4-5 capas de parénquima amilífero de células isodiamétricas que dejan pequeños espacios intercelulares y muestra algunas cámaras aerenquimáticas que se forman en la parte media cortical. La capa más interna de la corteza se diferencia en la endodermis con células redondeadas, con el primer engrosamiento en banda de Caspary. El cilindro central muestra el periciclo, también con células redondeadas y una estructura tetrarca (Fig. 6A), sin embargo se hallaron raíces con estructura anómala, con siete u ocho cordones xilemáticos. Cada cordón de floema presenta una célula laticífera, la cual tiene contorno poligonal en el corte transversal, y sus paredes delgadas están impregnadas con lípidos (Fig. 6A, B). La médula está formada por parénquima con células de paredes delgadas. En Ipomoea indica la estructura primaria de la raíz suma la presencia de drusas en el parénquima cortical y en el floema. En este además, hay un mayor número de células laticíferas. En una raíz de 1,0-1,2 mm de diámetro hallamos la estructura secundaria (Fig. 6C), con la peridermis donde se destaca la formación de súber y en las células del parénquima cortical hay almidón como reserva (si la raíz es de $I$. indica habrá drusas) (Fig. 6C). En un desarrollo inicial de la estructura secundaria la endodermis aún persiste y al ser desplazada hacia la periferia por el crecimiento secundario vascular, es aplastada y discontinua. En el cilindro central, el periciclo presenta células proporcionalmente grandes y, en el mismo, suelen aparecer células esclerificadas (Fig. 6C). En el floema secundario hay células laticíferas y el xilema secundario ocupa el centro de la raíz.

\section{Muehlenbeckia sagittifolia}

(Fig. 7A, B)

En una raíz de 0,3-0,5 mm de diámetro ya se encuentra estructura secundaria. Esta estructura presenta la peridermis con 2-4 estratos de súber e igual cantidad de parénquima, el cual en las capas internas muestra grupos de fibras dispuestas en círculo que rodean al floema secundario. El xilema secundario ocupa la totalidad del centro de la raíz. Se hallaron estiloides en las células del súber (Fig. 7B).

\section{Passiflora caerulea}

(Fig. 7C, D)

La estructura primaria tetrarca solo se puede observar en raíces de 0,2-0,3 mm de diámetro, luego es reemplazada por la estructura secundaria como se observa en una raíz de 2,0 mm de diámetro (Fig. 7C), con la peridermis, donde se destacan 6-8 estratos de súber. Una corteza parenquimática con grupos de fibras dispuestos al azar que rodean al anillo de floema secundario y éste al xilema secundario que ocupa el centro de la raíz (Fig. 7C). En la corteza abundan idioblastos taníferos y drusas y en el cilindro central, almidón (Fig. 7D).

\section{Smilax campestris}

(Fig. 7E, F)

Una raíz de 4,0 mm de diámetro presenta: rizodermis unistrata seguida de parénquima cortical de células isodiamétricas y paredes muy delgadas, a menudo las células periféricas están colapsadas y las 2-3 capas celulares internas, adyacentes a la endodermis, están esclerificadas, con paredes muy gruesas y puntuaciones, formando un anillo esclerenquimático (Fig. 7E). La endodermis presenta el tercer engrosamiento en U. El cilindro central presenta estructura poliarca con el periciclo y el parénquima adyacente esclerificados, incluso las células del parénquima medular tienen paredes engrosadas exhibiendo puntuaciones (Fig. 7E). En el parénquima medular hay granos de almidón simples, céntricos (Fig. 7F). 

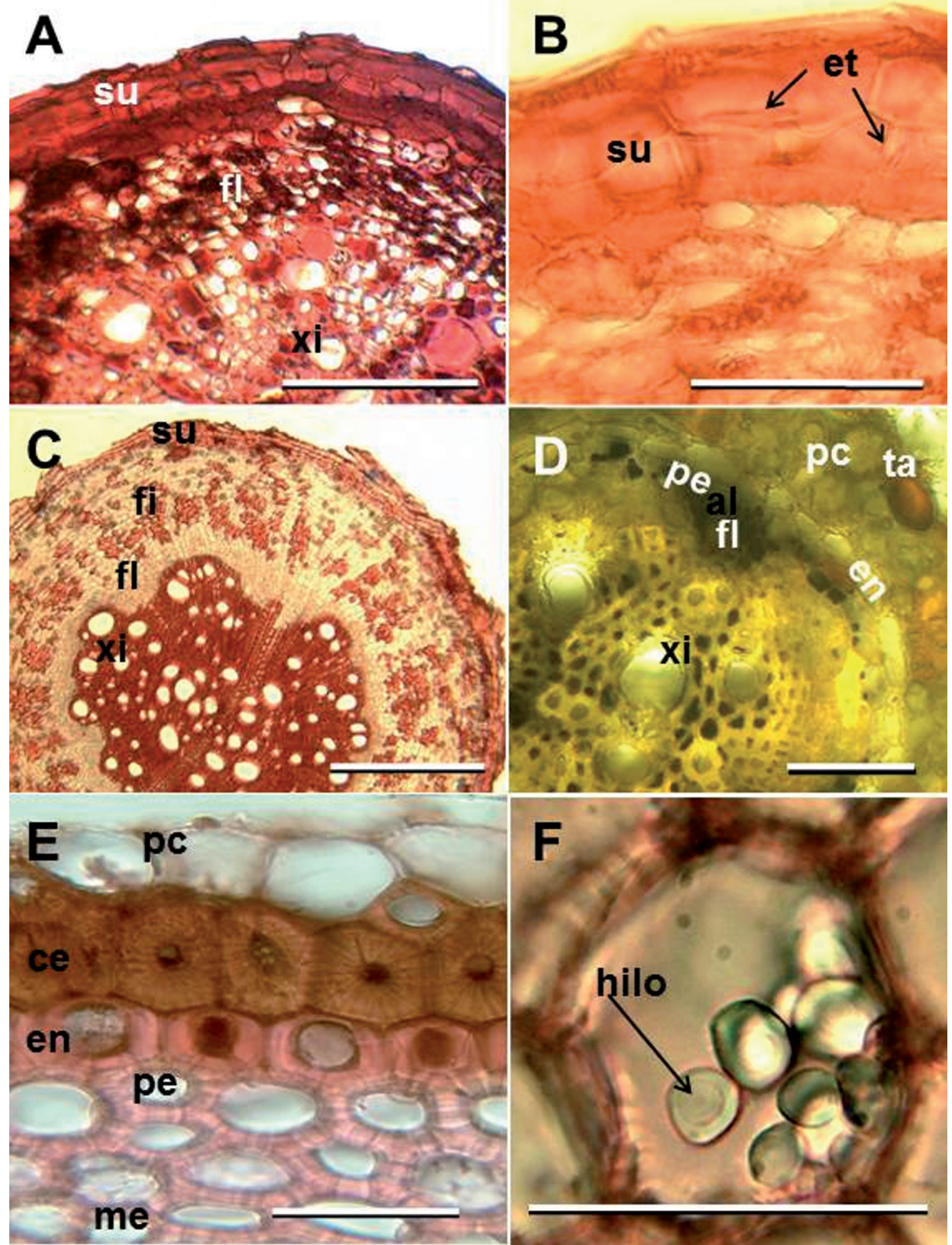

Fig. 7. Raíces, anatomía e histoquímica. Muehlenbeckia sagittifolia: A) Vista general de la estructura secundaria. B] Detalle del súber con estiloides. Passiflora caerulea: C] Vista general de la estructura secundaria. D) Detalle de identificación de taninos en el parénquima cortical y almidón en el cilindro central. Smilax campestris: E) Detalle de las células esclerificadas de la corteza formando un anillo de fibras junto a la endodermis, la cual muestra el tercer engrosamiento en $U$. En contacto con la endodermis, el periciclo y parénquima medular esclerificados. F) Detalle de granos de almidón con hilo céntrico en la médula. Ref.: al, almidón; ce, células esclerificadas; en, endodermis; et, estiloides; fi, fibras; fl, floema; me, médula; pc, parénquima cortical; pe, periciclo; su, súber; ta, tanino; xi, xilema. Escalas: A: 100 m; B, D, E, F: $50 \mu \mathrm{m}$; C: $500 \mu \mathrm{m}$. 
CLAVE PARA LA DETERMINACIÓN DE LAS ESPECIES BASADA EN LOS CARACTERES ANATÓMICOS DE LA RAÍZ

1 Raíz con floema secundario, atravesado en su parte media por grupos o un círculo continuo de fibras

Dolichandra unguis-cati

1' Raíz sin esas características ........... ?

2 Endodermis con tercer engrosamiento en U (Monocotiledóneas)

2' Endodermis con primer engrosamiento en banda de Caspary, visible como puntos de Caspary. Nunca alcanza el tercer engrosamiento en $U$ al ser eliminada o aplastada por el crecimiento secundario [Dicotiledóneas] ........................4 4

3 Parénquima cortical con las $2-3$ capas de células adyacentes a la endodermis con paredes engrosadas con puntuaciones, esclerificadas ............. Smilax campestris

3' Parénquima cortical sin esas características, abundante y formando raíces tuberosas. La exodermis conspicuamente desarrollada con 6-8 estratos celulares Herreria montevidensis

4 Raíces con presencia de cristales ..... 5

4' Raíces con ausencia de cristales. Presencia de células laticíferas en el floema Ipomoea cairica

5 Raíces con presencia de drusas ....... 6

5' Raíces con ausencia de drusas. Presencia de estiloides en el súber

Muehlenbeckia sagittifolia

6 Drusas en la corteza y en el floema. Presencia de estructuras secretoras de látex

6' Ausencia de estructuras secretoras de látex. Corteza con grupos de esclerénquima distribuidos al azar .........................

Passiflora caerulea

7 Presencia de esclereidas corticales ....... ....................... Araujia sericifera

7' Ausencia de esclereidas corticales Ipomoea indica

\section{DISCUSIÓN}

La estructura anómala de los tallos está bien documentada en diversas familias como las Amaranthaceae, Chenopodiaceae, Bignoniaceae, Convolvulaceae, Sapindaceae, etc. (Metcalfe y Chalk, 1965; Metcalfe, 1989). En Dolichandra unguis-cati (Bignoniaceae), el tallo presenta estructura anómala caracterizada por la división del floema en forma de cuñas penetrando en el xilema secunda- rio como es indicado por Metcalfe (1989). La parte subterránea también difiere de una morfología y estructura general, ya que presenta sectores estrechos y un engrosamiento tuberoso. Al analizar la anatomía, como se ha descripto se encontró una estructura intermedia entre el tallo y la raíz, se especula que puede pertenecer al hipocótilo. Esta suposición parece acordar bien con los resultados que obtuvieron Grosso y Kraus (2001) al estudiar el crecimiento y caracteres adaptativos de Dolichandra cynanchoides Cham. Sin embargo, consideramos que sería conveniente confirmar este supuesto con un estudio ontogenético de la especie. En Herreria montevidensis se observó otro engrosamiento, que corresponde al desarrollo de raíces fasciculadas tuberosas como lo indicaron Lahitte y Hurrell (2000); con respecto a las características estructurales e histoquímicas de la raíz (como la ausencia de almidón y la presencia de compuestos lipídicos en exodermis y endodermis) estuvieron de acuerdo con lo hallado en $H$. salsaparilha Martius por Almeida Gonçalves (2004). En Araujia sericifera (=A. hortorum E. Fourn.) la estructura de la raíz fue analizada por (Bayón y Arambarri, 1999; Bucciarelli et al., 2008) en el presente estudio se confirma y amplía la descripción de la misma e incluyen los resultados histoquímicos. En las raíces de ambas especies de Ipomoea estudiadas, la corteza presentó aerénquima y en el floema se halló un número variable de células con paredes delgadas que dieron reacción positiva para sustancias lipídicas, las que fueron llamadas células laticíferas por Metcalfe y Chalk (1950). En el rizoma de Smilax campestris la anatomía coincidió con las características descriptas por Gattuso (1995), a las cuales agregamos a través de la histoquímica la identificación de lípidos y taninos. Esto está de acuerdo con lo señalado para las raíces de Smilax subsessiliflora Duhamel por Ribeiro Guimarães et al. (2010). Igualmente, los rasgos estructurales de los órganos subterráneos de Muehlenbeckia sagittifolia y Smilax campestris, coinciden con los mencionados por Sella et al. (2013). La mayoría de las especies presentaron en el 
parénquima cristales de oxalato de calcio en las formas cristalinas de rafidios, estiloides y drusas. Se observó la presencia de rafidios en las Monocotiledóneas y de drusas o estiloides en Dicotiledóneas, coincidiendo con la conclusión de Prychid y Rudall (1999).

\section{CONCLUSIÓN}

En este trabajo se ha contribuido con descripciones morfológicas características estructurales e histoquímicas de los órganos subterráneos de las especies estudiadas y con las mismas se han generado claves de identificación, constituyendo una herramienta de valor en el control de calidad botánica.

\section{AGRADECIMIENTOS}

A la Secretaría de Ciencia y Técnica de la Universidad Nacional de La Plata por el financiamiento económico de los estudios en el marco del Programa de incentivos a los docentes-investigadores. Gracias a los evaluadores quienes con sus sugerencias han contribuido a mejorar del manuscrito.

\section{BIBLIOGRAFÍA}

Almeida Gonçalves L. 2004. Herreria salsaparilha Martius (Herreriaceae): anatomía, citogenética, citometría de fluxo e propagação in vitro. Tese apresentada a Universidade Federal de Viçosa, Minas Gerais, Brasil, 88 pp.

Alonso J., Desmarchelier C. 2005. Plantas medicinales autóctonas de la Argentina. Bases científicas para su aplicación en atención primaria de la salud. LOLA (Literature of Latin America), Buenos Aires, $663 \mathrm{pp}$.

Arambarri A. M., Novoa M. C., Hernández M. P., Colares M. N., Perrotta V. G. 2013. Anatomía de Dicotiledóneas: tallos de hierbas terrestres medicinales rioplatenses (Buenos Aires, Argentina). Bonplandia 22: 5-28.

Arambarri A. M., Hernández M. P., Perrotta V. G., Colares M. N., Novoa M. C. 2016. Anatomía de los órganos subterráneos de Monocotiledóneas medicinales rioplatenses (Argentina). I. Acuáticas y palustres. Lilloa 53: 157-172.

Barboza G. E., Cantero J. J., Núñez C. O., Ariza Espinar L. 2006. Flora medicinal de la provincia de Córdoba (Argentina),
Museo Botánico de Córdoba, Gráficamente ediciones, Córdoba, 1264 pp.

Barboza G. E., Cantero J. J., Núñez C., Pacciaroni A., Ariza Espinar L. 2009. Medicinal plants: A general review and a phytochemical and ethnopharmacological screening of the native Argentine Flora. Kurtziana 34: 7-365.

Battista S. M., García G. F., Rugna A. Z., Wagner M. L., Gurni A. A. 2007. Actividad antimicótica en extractos de diferentes órganos de Smilax campestris Griseb. - Smilacaceae. Boletin Latinoamericano y del Caribe de Plantas Medicinales y Aromaticas 6: 330-331.

Bayón N. D., Arambarri A. M. 1999. Anatomía y etnobotánica de las especies medicinales de la Provincia Pampeana: Asclepiadaceae. Acta Farmacéutica Bonaerense 18: 23-31.

Bucciarelli A., V. N. Cambi, C. Villamil. 2008. Morfoanatomía de Araujia hortorum E. Fourn. (Asclepiadaceae), especie nativa de interés medicinal. Phyton 77: 283295.

Cabanillas P. A., Hurrell J. A. 2012. Plantas trepadoras: tipo biológico y clasificación. Revista de Ciencias Morfológicas 14: 1-15.

Colares M. N., Hernández M. P., Novoa M. C., Perrotta V. G., Auguet S., Arambarri A. M. 2014. Anatomía comparada de raíces medicinales de hierbas terrestres rioplatenses (Buenos Aires, República Argentina). Dominguezia 30: 5-18.

Cosa M. T., Dottori N., Stiefkens L., Hadid M., Matesevach M., Delbón N., Wiemer P., Machado S., Cabrera V., Costa C., Pérez A., Trenchi A. 2014. Aplicaciones de técnicas de histología vegetal a la resolución de diversos problemas. Laboratorio de Morfología Vegetal, Facultad de Ciencias Exactas, Físicas y Naturales, Universidad Nacional de Córdoba, $133 \mathrm{pp}$.

de la Peña M. R., Pensiero J. F. 2004. Plantas argentinas. Catálogo de nombres comunes. LOLA (Literature of Latin America), Buenos Aires, 373 pp.

Debenedetti S. L., Miño J., Rojo A., Acevedo, M. C. D. 2000. Ensayo del efecto diurético de los extractos acuosos de Amaranthus muricatus (Moquin) Gill. ex Hicken, Bauhinia candicans Benth. y Smilax campestris Griseb. Acta Farmacéutica Bonaerense 19: 17-20.

Domínguez J. A. 1928. Contribuciones a la materia médica argentina. Instituto de Botánica y Farmacología (Facultad de Ciencias Médicas de Buenos Aires], Ed. Peuser, Buenos Aires, 433 pp. 
Ferrucci M. S, Cáceres Moral S. A., Galbany Casals M., Martínez W. J. 1999. Las plantas trepadoras del macrosistema Iberá. 13aㅡ Reunión de Comunicaciones Científicas y Técnicas, Facultad de Ciencias Agrarias, UNNE, pp. 1-4.

Gattuso S. J. 1995. Exomorfología y anatomía de Smilax campestris Griseb. (Smilacaceae). Acta Farmacéutica Bonaerense 14: 181-190.

Grosso M., Kraus T. 2001. Forma de crecimiento y caracteres adaptativos de Dolichandra cynanchoides Cham. (Bignoniaceae). Gayana Botánica 58: 153-161.

Guaglianone E. R., Hurrell J. A. 2009. Smilacaceae. En: Flora rioplatense. Monocotiledóneas [J. A. Hurrell, dir.) Parte 3, Vol. 4, LOLA (Literature of Latin America), Buenos Aires, 424 pp.

Hernández M. P., Colares M. N., Civitella S. M. 2009. Plantas utilizadas en

medicina popular en un sector del Partido de Berisso, Buenos Aires, Argentina. Boletín Latinoamericano y del Caribe de Plantas Medicinales y Aromáticas 8: 435-444.

Hernández M. P., Civitella S. M., Rosato V. G. 2010. Uso medicinal popular de plantas y líquenes de la Isla Paulino, provincia de Buenos Aires, Argentina. Boletín Latinoamericano y del Caribe de Plantas Medicinales y Aromáticas 9: 258-269.

Hernández M. P., Novoa M. C., Arambarri A. M., Oviedo M. A. 2015a. Plantas medicinales y para condimento usadas en el sudeste del partido de Berisso (Buenos Aires, Argentina). Bonplandia 24: 125138.

Hernández M. P., Novoa M. C., Civitella S. M., Mason D., Oviedo A. 2013. Plantas usadas en la medicina popular en la Isla Santiago, Buenos Aires, Argentina. Boletín Latinoamericano y del Caribe de Plantas Medicinales y Aromáticas 12 : 385-399.

Hernández M. P., Novoa M. C., Colares M. N., Perrotta V. G., Nughes L. M., Arambarri A. M. 2015b. Anatomía foliar de hierbas terrestres medicinales que crecen en la región rioplatense [Buenos Aires, Argentina). Bonplandia 24: 97123.

Hieronymus G. 1882. Plantas diaphoricae florae argentinae. Boletín de la Academia de Ciencias de Córdoba 4: 199-598.

Hurrell J. A. 2009. Herreriaceae. En: Flora rioplatense. Monocotiledóneas (J. A. Hurrell, dir.) Parte 3, Vol. 4. LOLA (Literature of Latin America), Buenos Aires, $424 \mathrm{pp}$.
Hurrell J. A., Ulibarri E. A., Arenas P. M., Pochettino M. L. 2011. Plantas de herboristería. Plantas medicinales que se comercializan en herboristerías de la ciudad de Buenos Aires. LOLA (Literature of Latin America), Buenos Aires, $242 \mathrm{pp}$.

Instituto de Botánica Darwinion- IBODA-CONICET. www.darwin.edu.ar / [consultado: junio 2017]

Johansen D. A. 1940. Plant microtechnique. McGraw-Hill Book Company, New York.

Lahitte H. B., Hurrell J. A. 1996. Las plantas de la medicina popular de la isla Martín García. Comisión de Investigaciones Científicas de la provincia de Buenos Aires (CICPBA). 246 pp.

Lahitte H. B., Hurrell J. A. 2000. Plantas trepadoras nativas y exóticas. LOLA ( Literature of Latin America), Buenos Aires, $264 \mathrm{pp}$.

Lahitte H. B., Hurrell J. A., Belgrano M. J., Jankowski L. S., Haloua M. P., Mehltreter K. 2004. Plantas medicinales rioplatenses. LOLA (Literature of Latin America), Buenos Aires, 240 pp.

Luque R., Sousa H. C., Kraus J. E. 1996. Métodos de coloração de Roeser (1972) -modificado- e Kropp (1972) visando a substituição do azul de astra por azul de alcião 8 GS ou $86 X /$ Staining methods of modified Roeser (1972) and Kropp (1972), aiming at substituting the astra blue by alcian blue 865 or $86 X$. Acta Botanica Brasilica 10: 199 - 212.

Mandrile E. L. 2003. Plantas medicinales que se dispensan en Argentina. Farmacognosia. Colegio de Farmacéuticos de la provincia de Buenos Aires. 289 pp.

Martínez Crovetto R. 1981. Plantas utilizadas en medicina en el noroeste de Corrientes (República Argentina). Miscelánea (Fundación Miguel Lillo) 69: 1-139.

Metcalfe C. R. 1989. Anomalous structure In: Metcalfe C. R., Chalk L. Anatomy of the Dycotiledons. Vol. II: 52-63. Oxford University Press.

Metcalfe C. R., Chalk L. 1950. Anatomy of the Dycotiledons 1: 1- 763. Oxford University Press.

Metcalfe C. R., Chalk L. 1965. Anatomy of the Dycotiledons 2: 764-1499. Oxford University Press.

Novoa M. C., Arambarri A. M. 2016. Importance of anatomical leaf-blade features for characterization of medicinal Commelinaceae in the Rio de la Plata area (Buenos Aires, Argentina). Boletín de la Sociedad Argentina de Botánica 51: 419-427. 
Novoa M. C., Colares M. N., Arambarri A. M. 2012. Anatomy of Monocotyledons: stems and rhizomes of land herbs used as medicinal in the Rio de la Plata area (Argentina). Bonplandia 21: 53-61.

Perrotta V. G., Hernández M. P., Arambarri A. M. 2017. Anatomía de los órganos subterráneos de cuatro Dicotiledóneas medicinales rioplatenses (Argentina). II. Plantas palustres. Lilloa 54 (2): 229239.

Pochettino M. L., Martínez M. R., Itten B., Zucaro M. 1997. Las plantas medicinales como recurso terapéutico en una población urbana: estudio etnobotánico en Hernández (Pdo. La Plata, Prov. Buenos Aires, Argentina). Parodiana 10: 141-152.

Prychid C. J., Rudall P. J. 1999. Calcium oxalate crystals in Monocotyledons: a review of their structure and systematics. Annals of Botany 84: 725-739.

Ribeiro Guimarães A., Gonçalves Costa C., Potsch Andreata R. H. 2010. Morfoanatomia do sistema subterrãneo de Smilax subsessiliflora (Smilacaceae). Rodriguesia 61: 181-194.

Rondina R. V. D., Bandoni A. L., Coussio J. D. 2008. Especies medicinales argentinas con potencial actividad analgésica. Dominguezia 24: 47-69.

Rondina R. V. D., Bandoni A. L., Coussio J. D. 2010. Argentine medicinal plants with potential antifungal activity. Dominguezia 26: 31-39.

Rugna A., Gurni A. A., Wagner M. L. 2005. Fitoquímica comparative de flavonoids en los diferentes órganos de Smilax campestris Griseb. -Smilacaceae. Dominguezia 21: 17-23.

Rugna A. Z., Gurni A. A., Wagner M. L. 2007. Ritmo de producción de los polifenoles de Smilax campestris Griseb. [Smilacaceae). Boletín Latinoamericano y del Caribe de Plantas Medicinales y Aromáticas 6: 297-298.

Rugna A., Polo J., Evelson P., Gurni A. A., Llesuy, S., Wagner M. L. 2003. Antioxidant activity in rhizomes from Smilax campestris Griseb. Smilacaceae. Molecular Medicinal Chemistry 1: 21-25.

Ruzin S. E. 1999. Plant microtechnique and microscopy. University Press, Oxford, $323 \mathrm{pp}$.

Sella M., Debenedetti S., Valle C., Gattuso S., Di Bernardi T., Spegazzini E. 2013. Parámetros histoanatómicos para el reconocimiento de dos especies denominadas "zarzaparrilla". Presentado en SILAE XXII, Costa Rica. Págs. 105-106. https://revistas.ucr.ac.cr/index.php/clinica/article/download/13130/12402

Toursarkissian M. 1980. Plantas medicinales de la Argentina. Ed. Hemisferio Sur, Buenos Aires. 178 pp.

Tropicos - Home. www.tropicos.org/ [consultado: junio 2017].

Zarlavsky G. E. 2014. Histología vegetal. Técnicas simples y complejas. Sociedad Argentina de Botánica, 198 pp.

\section{APÉNDICE 1}

Lista en orden alfabético de nombres científicos de las especies estudiadas con su familia, nombres vulgares, uso popular y actividad biológica. Los usos están referidos a los órganos subterráneos.

\section{Araujia sericifera \\ (Apocynaceae)}

«Doca. Isopa. Pajarito. Tas. Tasi. Taso. Taxi. Taxo». Enredadera perenne con látex. Usos: El cocimiento de la raíz en el mate es galactógeno (Bucciarelli et al., 2008). El látex contiene caucho y resinas (Domínguez, 1928) y es analgésico odontálgico (Lahitte y Hurrell, 2000; Lahitte et al., 2004; Barboza et al., 2006; Rondina et al., 2008). El látex posee actividad proteolítica, determinada en el fruto (Barboza et al., 2009).

\section{Dolichandra unguis-cati (Bignoniaceae)}

«Charrúa. Mbaracayá-piapé. Teyú igsipó. Uña de gato». Liana perenne. Usos: la tintura o jarabe de la raíz es astringente y antidisentérico (Lahitte y Hurrell, 2000; Lahitte et al., 2004); galactógena (Barboza et al., 2009). La raíz contiene oxidasas (Domínguez, 1928); la raíz seca contiene triterpenos (Barboza et al., 2009).

\section{Herreria montevidensis (Herreriaceae)}

«Mandió zarza. Zarza. Zarza blanca. Zarzaparrilla blanca». Enredadera perenne. Usos: La decocción de las raíces se bebe como digestivo, hepático, depurativo, diurético, antinefrítico, para enfermedades venéreas, antirreumático y artrífugo, en el norte de Argentina también se bebe como remedio 
antiácido, purgante, antigotoso y para activar la circulación sanguínea o infecciones de vejiga y en uso externo como cicatrizante de heridas. (Lahitte y Hurrell, 2000; Lahitte et al., 2004; Hurrell, 2009). Posee propiedades como analgésico en enfermedades de vejiga (Rondina et al., 2008). Es comercializada en herboristerías (Lahitte y Hurrell, 2000; Hurrell, 2009).

\section{Ipomoea cairica \\ (Convolvulaceae)}

«Bejuco.Campanilla. Mechoacán. Suspiros». Enredadera perenne. Usos: el cocimiento de las raíces se bebe como purgante, febrífugo, antihidropónico y externamente en fomentos se aplica como vulnerario y antidermatósico (Lahitte y Hurrell, 2000; Lahitte et al., 2004). El látex puede estar acompañado de resina (Domínguez, 1928). Actividad biológica de la raíz no testeada (Barboza et al., 2009).

\section{Ipomoea indica \\ (Convolvulaceae)}

«Batatilla. Bejuco. Caá-parí. Suspiros». Enredadera, perenne. Usos: igual que $I$. cairica (Lahitte Hurrell, 2000). Raíz posee propiedades como purgante, febrífugo y vulnerario.

\section{Muehlenbeckia sagittifolia (Polygonaceae)}

«Falsa zarzamora. Mollaco. Quilo. Zarza colorada. Zarza negra. Zarzamora. Zarzaparrilla. Zarzaparrilla colorada». Liana perenne. Usos: la decocción de la raíz en el agua del mate posee propiedades como depurativo, cardiotónico, refrescante y antisifilítico (Martínez Crovetto, 1981; Lahitte y Hurrell, 1996; Lahitte et al., 2004; Barboza et al., 2009; Hurrell et al., 2011). Como tópico es astringente y vulnerario (Lahitte y Hurrell, 2000; Barboza et al., 2009) y cicatrizante (Lahitte et al., 2004). Posee taninos (Domínguez, 1928). Contiene taninos, alcaloides, esteroides, quinonas y saponinas (Lahitte y Hurrell, 2000). Es comercializada en herboristerías (Hurrell et al., 2011).

\section{Passiflora caerulea \\ (Passifloraceae)}

«Flor de la pasión. Granadilla. Mburucuyá. Mburukujá guasú. Pasionaria». Liana, perenne. Usos: la raíz es vermífuga y desinflamante (Lahitte y Hurrell, 1996, 2000; Mandrile 2003). La infusión de la raíz se bebe contra la pulmonía (Lahitte y Hurrell, 1996; Lahitte et al., 2004). Emenagogo, anticonceptivo (Alonso y Desmarchelier, 2005). Antiespasmódico, antihelmíntico, antiflogístico, tóxico y narcótico (Barboza et al., 2006, 2009). Se comercializa en herboristerías (Hurrell et al., 2011).

\section{Smilax campestris \\ (Smilacaceae)}

«Sacha mora. Salsaparrilla. Verdenazo. Zarza blanca. Zarza espinosa. Zarzamora. Zarzaparrilla. Zarzaparrilla blanca». Liana perenne. Esta especie aparece en la Farmacopea Argentina en 1921 (Lahitte y Hurrell, 2000). Usos: los órganos subterráneos para enfermedades renales y de las vías urinarias (Martínez Crovetto, 1981; Lahitte y Hurrell, 1996). La decocción de los rizomas y raíces se emplean como diurético, sudorífico, desinflamante, depurativo, tónico, refrescante, laxante, antiartrítico y antirreumático, también tendría propiedades como antisifilítico y analgésico (Sella et al., 2013; Lahitte et al., 2004; Rondina et al., 2008; Barboza et al., 2009; Guaglianone y Hurrell, 2009; Hurrell et al., 2011). Los rizomas producen flavonoides y tienen actividad antioxidante (Rugna et al., 2003, 2005), sin embargo el contenido de flavonoides tiene variación con el estado fenológico de la especie (Rugna et al., 2007). Los órganos subterráneos por su contenido en saponinas poseen propiedad antimicótica (Domínguez, 1928; Lahitte et al., 2004; Battista et al., 2007; Guaglianone y Hurrell, 2009). El rizoma posee actividad antioxidante y en su composición química se halló: quercetina, 3-glucosido, 3-ruinosida, procianidina, propelagonidina, flavonoides (Barboza et al., 2009). La actividad diurética no pudo ser probada a través de la metodología clásica (Debenedetti et al., 2000). Es 
comercializada en herboristerías y a veces, es adulterada con $M$. sagittifolia (Hurrell et al., 2011). Se recomienda no consumir dosis altas por los efectos tóxicos (Lahitte y Hurrell, 2000). 